\title{
Symptomatic Parietal Intradiploic Encephalocele- A Case Report and Literature Review
}

\author{
Chen Shi ${ }^{1}$ Bruno Flores ${ }^{1}$ Stephen Fisher ${ }^{2}$ Samuel L Barnett ${ }^{3}$ \\ ${ }^{1}$ Department of Neurosurgery, University of Texas Southwestern \\ Medical Center, Dallas, Texas, United States \\ 2 Department of Radiology, University of Texas Southwestern Medical \\ Center, Dallas, Texas, United States \\ 3 Department of Neurological Surgery, University of Texas \\ Southwestern Medical Center, Dallas, Texas, United States

\begin{abstract}
Address for correspondence Samuel L. Barnett, MD, Department of Neurological Surgery, 5303 Harry Hines Blvd, 6th Floor, Suite 108, Dallas, TX 75390-9167, United States (e-mail: Sam.Barnett@UTSouthwestern.edu).
\end{abstract} \\ J Neurol Surg Rep 2017;78:e40-e45.
}

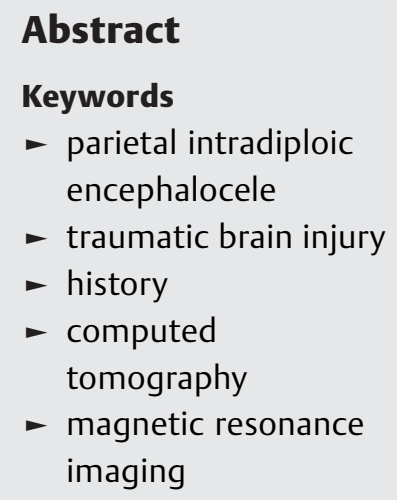

Encephalocele is a rare condition that consists of herniation of cerebral matter through openings of dura and skull. A majority of encephaloceles are congenital and manifest in childhood. We present a case of a 45 -year-old man presenting with contralateral hemiparesis and found to have an extremely rare phenomenon of a symptomatic posttraumatic parietal intradiploic encephalocele (IE) manifesting 36 years following pediatric traumatic head injury. Computed tomography and magnetic resonance imaging confirmed herniation of brain tissue into the intradiploic space. Surgical treatment with reduction of the encephalocele achieved near resolution of preoperative hemiparesis on follow-up. The pathogenesis and a literature review of IE are discussed.

\section{Introduction}

Encephalocele is a rare condition that consists of herniation of cerebral matter through openings of dura and skull. They can be either acquired or congenital. The incidence of the congenital form is estimated to be 1 per 3,000 to 10,000 live births. ${ }^{1,2}$ Many classification systems for encephalocele exist; however, the most widely accepted is that from Matson and Ingraham, ${ }^{3}$ based on the location of the encephalocele: basal, sincipital, convexity, and atretic. Convexity encephalocele, subdivided into frontal, parietal, occipital, and cervico-occipital, is the most common type. ${ }^{3}$ Those lesions are usually located at midline, extending from the nasal region to the occiput, although off midline temporal regions have also been reported. ${ }^{4,5} \mathrm{~A}$ majority of the encephaloceles are congenital and manifest in childhood. Here, we report a rare case of a traumatic intradiploic encephalocele (IE) presenting with contralateral hemiparesis several decades after an initial pediatric trauma.

\section{Case Report}

\section{History and Examination}

A 45-year-old Caucasian, right-handed man presented to our emergency department (ED) with 3 to 4 weeks history of progressive gait disturbances and left lower extremity weakness. His pertinent medical history was negative for any recent history of head trauma, but was significant for a moderate traumatic brain injury (TBI) at the age of 9 years, where he fell off a tree and sustained a closed parietal skull fracture with no posttraumatic cognitive or neurologic deficits. He had no history of seizures, central nervous system infections, stroke, or brain tumor. His neurological exam at admission was significant for left hemiparesis (strikingly more pronounced on lower than upper extremity) and positive left pronator drift testing. A positive Babinski sign could be elicited on the left. He was initially seen in the ED where a magnetic resonance imaging (MRI) showed IE of the right parasagittal parietal bone containing portions of the right precentral gyrus and received

October 22, 2016

accepted after revision

January 2, 2017
DOI http://dx.doi.org/

10.1055/s-0037-1599799.

ISSN 2193-6366. (c) 2017 Georg Thieme Verlag KG Stuttgart · New York
License terms

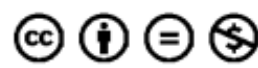




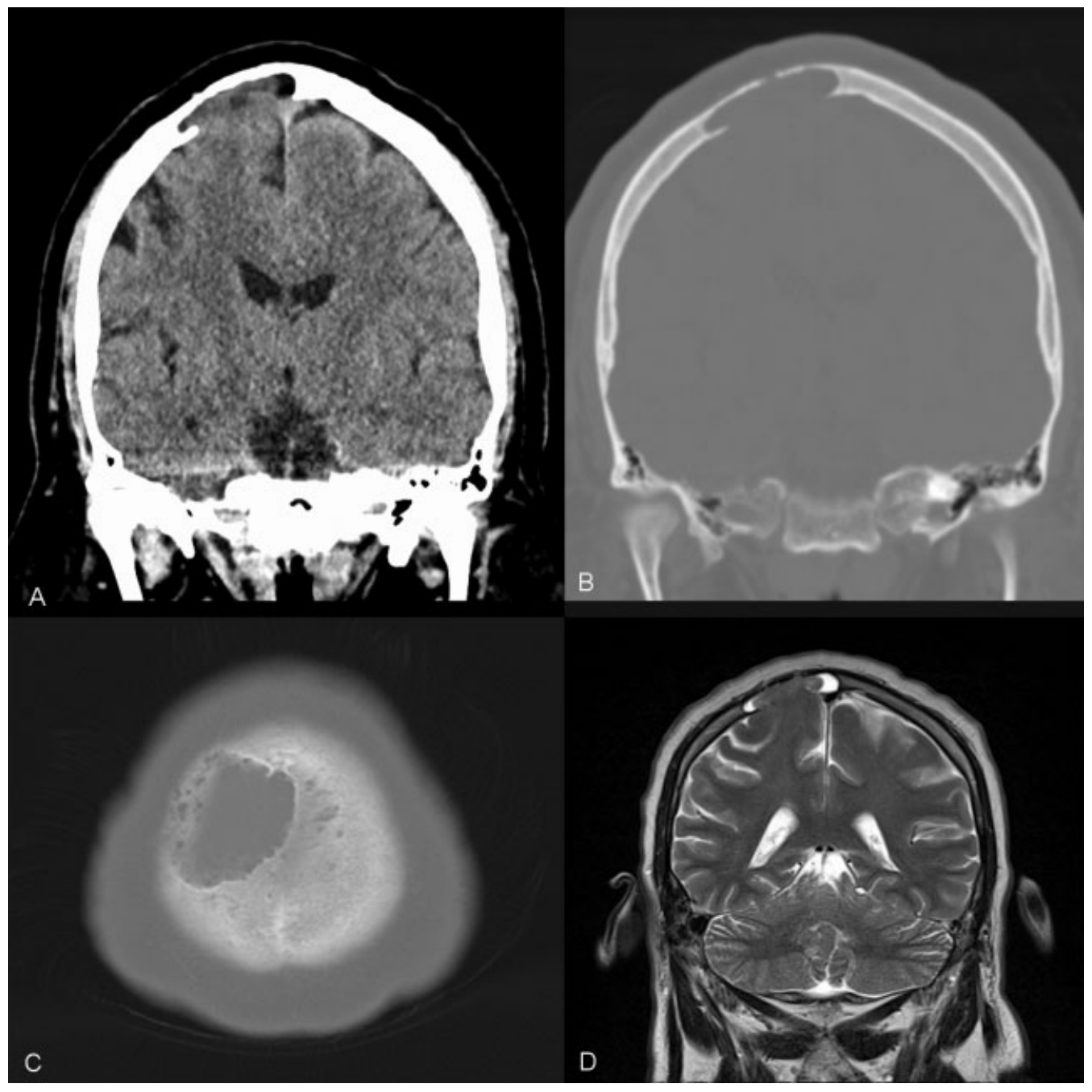

Fig. 1 A 3-mm (A, B) coronal and (C) axial reformats in both (A) brain and (B) bone windows on (D) CT and coronal MRI showing herniated brain parenchyma. $\mathrm{CT}$, computed tomography; MRI, magnetic resonance imaging.

surrounding brain parenchyma ( - Fig. 1D). There were no bony deformities upon palpation of scalp.

\section{Preoperative Neuroimaging}

Noncontrasted computed Tomography (CT) demonstrated a well-circumscribed, $4.3 \times 3.7 \mathrm{~cm}$ area of osteolysis in the right parasagittal parietal bone, with internal soft tissue attenuation ( $\mathbf{- F i g}$. 1A-C), complete erosion of the inner table, and noncontiguous lytic changes of the outer table ( -Fig. 1B, C). MRI with and without gadolinium contrast administration demonstrated a right parasagittal dural defect with intradiploic herniation of the right precentral gyrus ( - Fig. 1D). There was no restricted diffusion to suggest acute infarction (-Fig. 2A-D).

\section{Preoperative Hospital Course}

After initial neurosurgical evaluation in the ED, the patient was admitted to the neurosurgical ward and started on dexamethasone $4 \mathrm{mg}$ intravenously every 6 hours. His left lower extremity weakness responded positively to the initial steroids therapy, with partial but transient improvement on his leg weakness to antigravity strength and ambulatory with a rolling walker. He was reluctant to proceed with surgical intervention initially, and elected to continue hospital observation for a few days. Since no sustainable improvement on his strength was seen after 2 days of high-dose dexamethasone treatment, he decided to proceed with surgical intervention.

\section{Operative Procedure}

Under general anesthesia, and using CT-guided intraoperative frameless stereotactic navigation, the area correspondent to the encephalocele was identified and marked. The calvarium was exposed through a bicoronal incision. The bone overlying the encephalocele appeared to be mottled and thin. Cortical brain matter was visualized directly underneath the most thinned portions of the right parietal bone. It appeared pale with no evidence of cortical vasculature, and the usual gyral anatomy had been lost. Starting from the areas of bone dehiscence, the craniectomy was then extended centrifugally until identification of the normal inner table surrounding the whole encephalocele. Once the margins of the encephalocele were completely identified and dissected, a large craniotomy incorporating the bone defect 


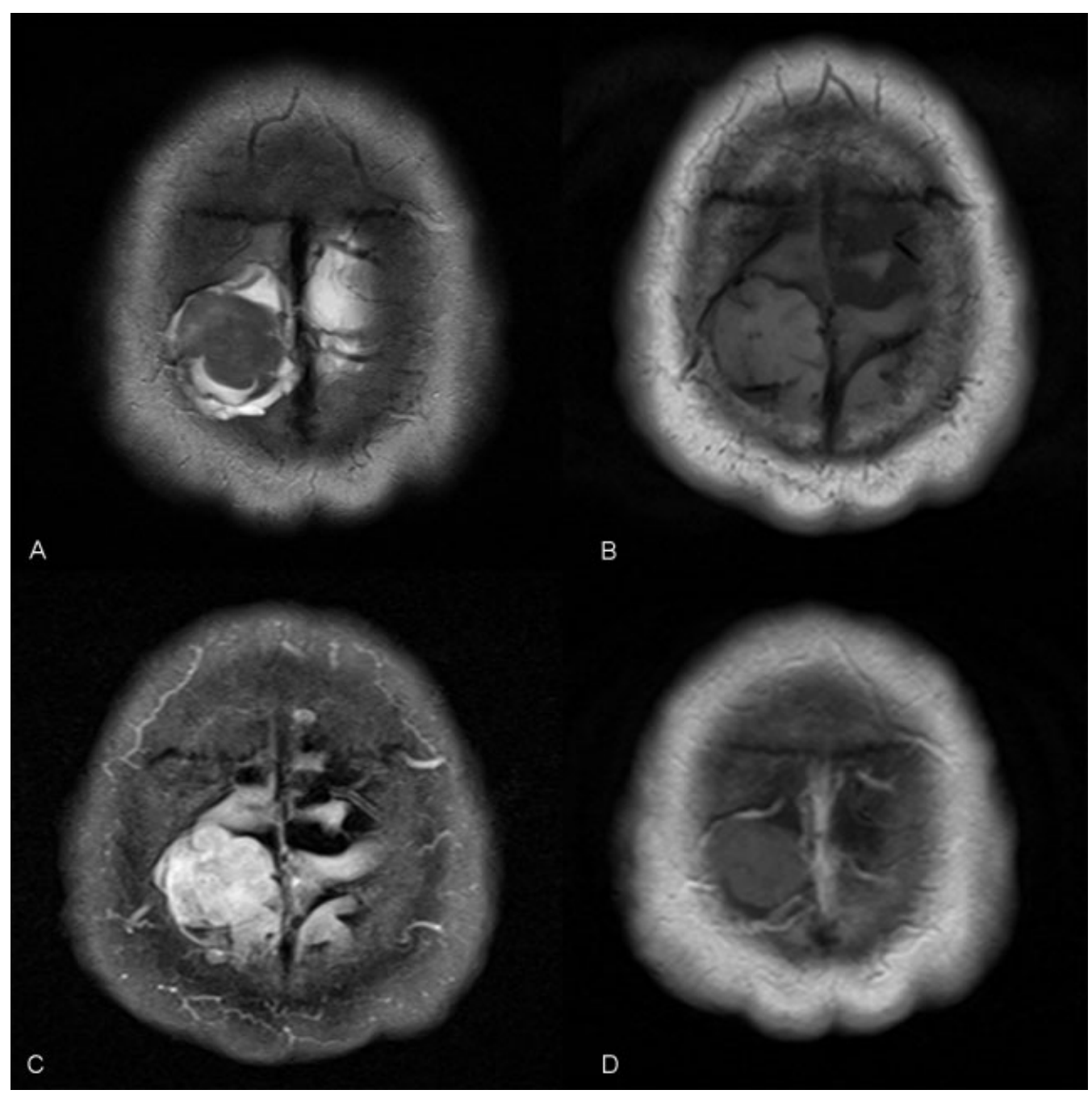

Fig. 2 (A) Axial 5 mm SE) T2 images, (B) axial 5 mm blood suppressed SE T1 images, (C) axial 5 mm FLAIR images, and (D) axial 5 mm postcontrast SE T1 images (12 mm Gadavist). CT, computed tomography; MRI, magnetic resonance imaging; SE, spin echo.

was completed using high-speed craniotome (- Fig. 3). Despite an extensive stellate-shaped dural opening and encephalocele decompression, we were unsuccessful on reducing the encephalocele through the pial opening. The pial-arachnoid plane surrounding that area was very sclerotic and firmly adherent to the encephalocele pedicle. Due to the risk of vascular injury to an already friable but apparently still eloquent brain, we decided not to proceed with arachnoidal opening or resection of the encephalocele sac. An expansile duraplasty was completed using a pericranial autograft. The bone flap was replaced with a titanium mesh used for coverage over the craniectomy site.

\section{Perioperative Course and Follow-up}

He tolerated the procedure well and was kept in intensive care unit for 24 hours without complications. Postoperative noncontrasted CT head revealed no ischemic changes on the surrounding parenchyma and adequate reduction of the encephalocele (-Fig. 4A-C).

He was transported to the neurosurgery ward in stable condition. He was discharged with mild improvement in left hemiparesis. On 2-month follow-up, his preoperative left leg weakness has greatly improved with near resolution of preoperative hemiparesis.

\section{Discussion}

A cephalocele is a protrusion of cerebral contents through a defect in the dura or skull. These lesions are classified according to their location and contents (meninges, brain parenchyma, ventricles, and/or vasculature). The presence of brain parenchyma characterizes an encephalocele, whereas those without brain parenchyma are called meningocele. The location of these lesions varies as they may involve the posterior fossa, occipital, basal, frontoethmoidal, and/ or parietal regions. ${ }^{6-8}$ Depending on the etiology, cephaloceles are further classified as primary or secondary. In the case of primary cephaloceles, a congenital defect exists in the dura or skull, usually at the site of a cranial suture, representing a midline closure defect of the neural tube. In secondary cephaloceles, a preceding injury such as infection, tumor, trauma, or surgery is usually the underlying cause.

In this case report, we present an extremely rare phenomenon of a symptomatic posttraumatic parietal IE 


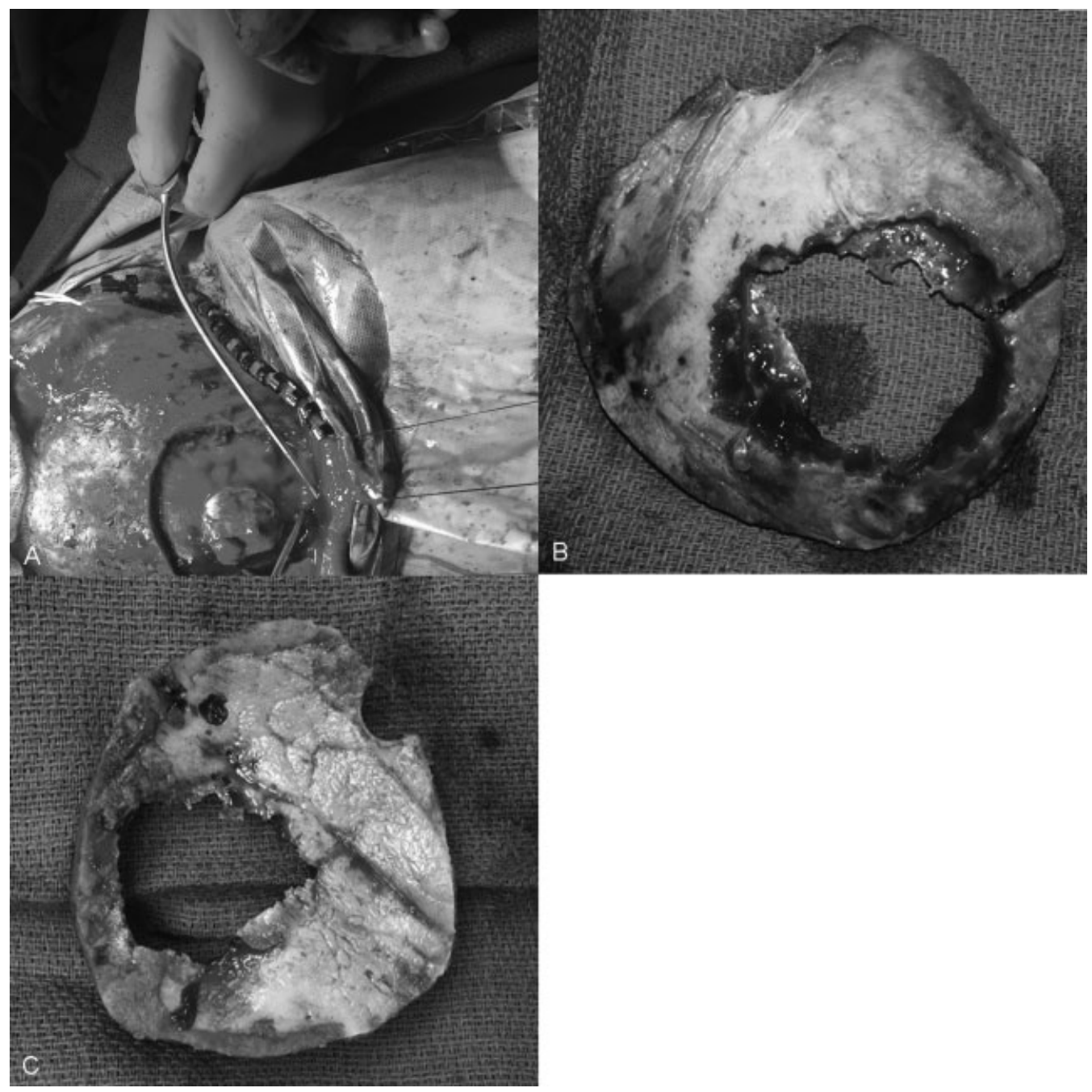

Fig. 3 (A) Intraoperative picture showing large craniotomy incorporating the bone defect. The pial-arachnoid plane surrounding that area was very sclerotic and firmly adherent to the encephalocele pedicle. The defect was shown in (B) and (C) for dorsal and ventral side, respectively.

manifesting 36 years following traumatic head injury. IE is a relatively poorly described clinical entity. Medline and PubMed database literature search revealed only 11 cases previously reported in the literature.

- Table 1 summarizes the key findings of these articles. Of these cases, five had no history of trauma, four cases ${ }^{9-11}$ (including the present study) were found to be posttraumatic and/or iatrogenic, and one did not comment on any supposed etiology for the encephalocele. ${ }^{12}$ Therefore, traumatic injuries to the skull were the reported etiology of the cephalocele in approximately $40 \%$ of the literature cases. The initial insult typically occurs in childhood with a delayed diagnosis decades later after manifestation of signs and symptoms, if at all. ${ }^{13-16}$

Of the ones who did report head trauma, most presented months to a year after the traumatic injury. Patil and Etemadrezaie $^{9}$ reported a 64-year-old man had head trauma 8 months prior to experiencing an enlarging palpable scalp mass. Lenthall and Penney ${ }^{10}$ reported a 15 -month-old infant sustained a head injury and presented with growing fracture with pulsatile mass 9 months later. Our patent presented with progressive hemiparesis 36 years following pediatric traumatic head injury.
Depending on where the lesion is, symptoms may vary widely, from seizures to aphasia, numbness, hemiparesis, or even asymptomatic. Of the case reports, the most common symptoms are hemiparesis/weakness ${ }^{11,12,17}$ (four patients including the present study), seizures ${ }^{5,17}$ (two patients), palpable mass ${ }^{9,10}$ (two patients); one was incidentally found. ${ }^{18}$

Surgical repair with or without excision of the herniated brain parenchyma is generally performed in symptomatic patients. Clinical response is generally favorable with minor improvement in symptoms to completely asymptomatic on follow-up.

In order for an encephalocele to occur, the inner table and dura must be breached. The exact mechanism of posttraumatic IE is not well defined. A few theories have been proposed. D'Almeida and King ${ }^{19}$ postulated that if only the inner table and dura mater are affected by the fracture from TBI, the diploic space is opened and enlarged over time by pulsation of cerebrospinal fluid (CSF). Lenthall and Penney ${ }^{10}$ stressed the importance of an outward driving force for enlargement of the diploic space secondary to normal brain growth, CSF pulsatility, or increased intracranial pressure, as also seen in the coughing spell reported by Loumiotis et al. ${ }^{12}$ Patil and 

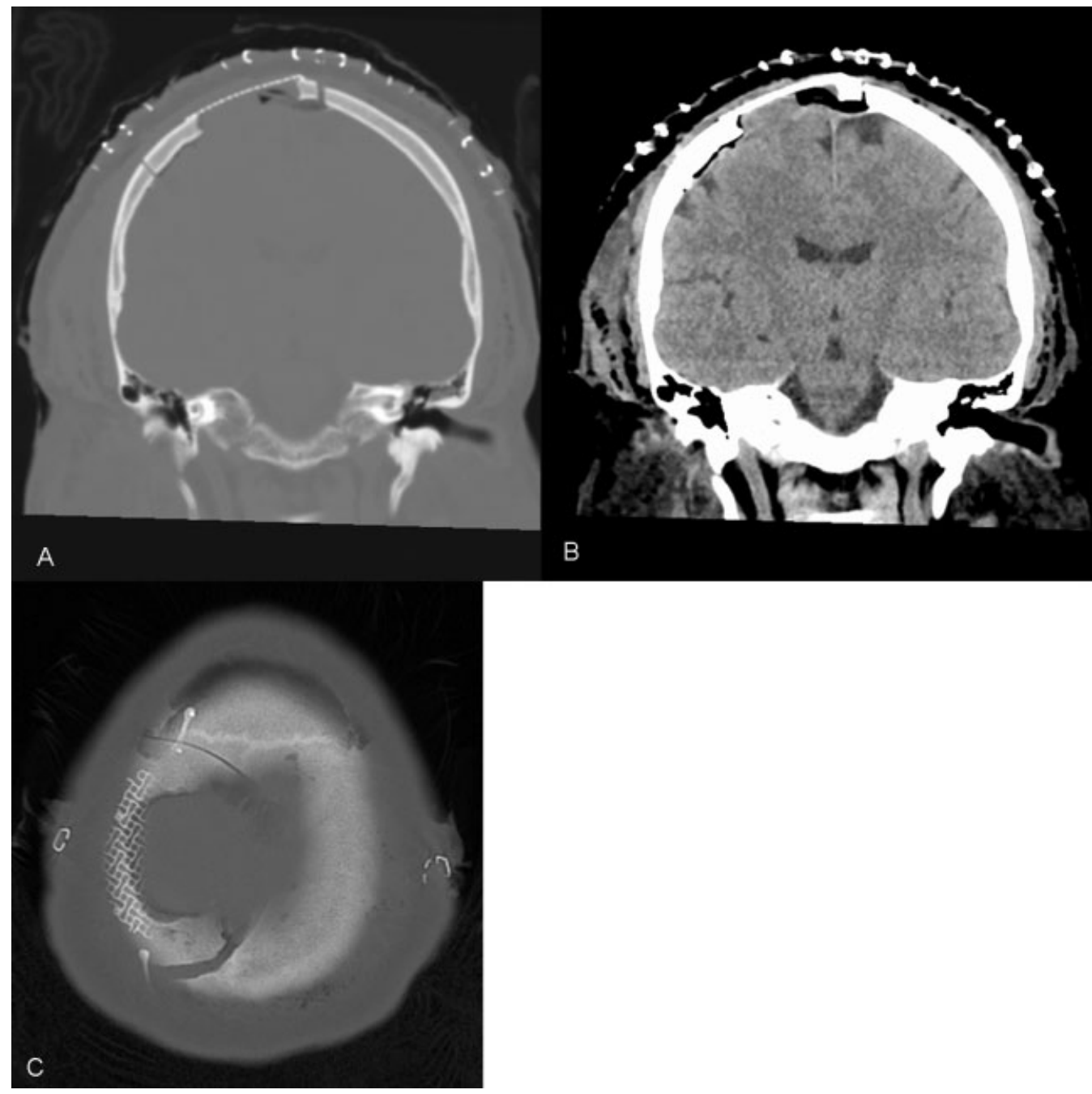

Fig. 4 (C) A 3-mm axial bone window and coronal reformats in both (B) brain and (A) bone windows on postoperative CT. CT, computed tomography.

Table 1 Review of intradiploic encephalocele articles

\begin{tabular}{|c|c|c|c|c|c|c|}
\hline Author (year) & Site & $\begin{array}{l}\text { Patient age, } \\
\text { sex }\end{array}$ & Signs and symptoms & $\begin{array}{l}\text { History of } \\
\text { trauma }\end{array}$ & Surgical repair & Follow-up \\
\hline Patil and Etemadrezaie (1996) & Parietal & $64 \mathrm{y}, \mathrm{M}$ & Enlarging palpable scalp mass & Yes & $\begin{array}{l}\text { Yes with excision of } \\
\text { herniated brain }\end{array}$ & Asymptomatic \\
\hline Lenthall and Penney (1999) & Occipitoparietal & $15 \mathrm{mo}, \mathrm{NR}$ & $\begin{array}{l}\text { Growing fracture with } \\
\text { pulsatile mass }\end{array}$ & Yes & Yes $^{\mathrm{a}}$ & NR \\
\hline $\begin{array}{l}\text { Arevalo-Perez and Millán-Juncos } \\
\text { (2015) }\end{array}$ & Parietal & 84 y, F & Incidental finding & No & No & NR \\
\hline Loumiotis et al (2010) & Frontal & $50 \mathrm{y}, \mathrm{M}$ & RUE weakness & NR & Yes, decompression & $\begin{array}{l}\text { Progressive but incomplete } \\
\text { improvement }\end{array}$ \\
\hline Tsuboi et al (2007) & Parietal & 66 y, M & Dizziness & No & No & 5 y asymptomatic \\
\hline Peters et al $(2002)^{22}$ & Parietal & 36 y, M & RLE coordination & No & Yes, with excision & Asymptomatic \\
\hline Martínez-Lage et al (1997) & Frontal & $6 y, F$ & $\mathrm{~L}$ hemiparesis & latrogenic & Yes, without resection & Benign \\
\hline Kosnik et al (1976) & Parietal & $57 \mathrm{y}, \mathrm{M}$ & Seizure, expressive aphasia & No & $\begin{array}{l}\text { Yes with excision of } \\
\text { herniated brain }\end{array}$ & Asymptomatic \\
\hline Fountas et al (2005) & Parietal & $61 \mathrm{y}, \mathrm{F}$ & Seizures, LUE monoparesis & No & $\begin{array}{l}\text { Yes with excision of } \\
\text { herniated brain }\end{array}$ & 26 mo, no deficit, size free \\
\hline Present case & Parietal & $45 \mathrm{y}, \mathrm{M}$ & L hemiparesis & Yes & Yes, without excision & $\begin{array}{l}\text { Minor improvement lost to } \\
\text { follow-up }\end{array}$ \\
\hline
\end{tabular}

Abbreviation: NR, not reported; LLE, left lower extremity; LUE, Left upper extremity; RLE, Right lower extremity; RUE, Right upper extremity. ${ }^{\text {a }}$ Not specified what kind. 
Etemadrezaie $^{9}$ proposed that low-velocity blunt injury may fracture only the inner table, which is thinner. The fractured inner table depresses and recoils during the initial impact. The depression tears the dura and the recoil creates a negative pressure that forces the underlying arachnoid and brain into the diploic space. The lesion then increases in size with CSF pulsation.

Menkü et $\mathrm{al}^{13}$ proposed that there could be congenital factors, although the article focused on intradiploic pseudomeningocele as opposed to IE. They proposed that intradiploic cyst develops through foveolae granulare which are anatomical and physiological defects that form a hollow space of the inner table. These granulations usually lie in the frontoparietal bone and near the superior sagittal sinus. In the setting of head trauma, dura and arachnoid membranes are breached without skull fracture. CSF pulsation then enlarges the intradiploic space with time. The communication could also allow brain parenchyma to herniate into the diploic space.

IE can be seen on CT as a lytic lesion. Differential diagnosis includes epidermoid or dermoid cyst, cavernous hemangioma, eosinophilic granuloma, plasmacytoma, metastasis, and osteosarcoma. ${ }^{18}$ MRI is necessary to establish a diagnosis. Herniation of brain parenchyma through a dural defect into intradiploic space is what separates this lesion from the rest on the differential, as is seen in our case. Coronal and sagittal imaging provides the optimal assessment. However, definitive diagnosis still lies in surgical exploration and histopathological examination. ${ }^{13,20,21}$

Surgical correction with craniotomy, reduction of herniated cortex, excision of herniated parenchyma, and cranioplasty have been reported as the optimal management strategy. If a patient remains asymptomatic, observation and regular follow-up may be adequate. Surgical excision of the herniated brain parenchyma depends on the proximity to the location of the vital functional areas of the brain such as the motor cortex. In our case, because of the risk of vascular injury to an already friable but apparently still eloquent brain, we decided not to proceed with arachnoidal opening or resection of the encephalocele sac.

Care must be taken on surgical planning. Functional MRI, magnetic source imaging of evoked sensory potential, or intraoperative cortical mapping have been used to help with defining eloquent cortex. ${ }^{17}$ Frameless neuronavigational systems as used in our case are recommended to enhance precision. Regardless of the method, meticulous dissection must be exercised to maximize recovery and minimize complications.

IE is extremely rare. Our case report adds another case to the existing literature. This case is unique in that the patient became symptomatic several decades after a pediatric head trauma.

\section{Disclosure \\ None.}

\section{Acknowledgments}

We thank Dr. Awais Vance for input in the radiology figures; Dr. Ben Kafka, Carl Youssef, and Sananthan
Sivakanthan for information gathering and providing ideas.

\section{References}

1 Mealey J Jr, Dzenitis AJ, Hockey AA. The prognosis of encephaloceles. J Neurosurg 1970;32(02):209-218

2 Martínez-Lage JF, Poza M, Sola J, et al. The child with a cephalocele: etiology, neuroimaging, and outcome. Childs Nerv Syst 1996;12(09):540-550

3 Matson DD, Ingraham FD. Neurosurgery of Infancy and Childhood, 2nd ed. Springfield, IL.: Thomas; 1969

4 Tsuboi Y, Hayashi N, Noguchi K, Kurimoto M, Nagai S, Endo S. Parietal intradiploic encephalocele-case report. Neurol Med Chir (Tokyo) 2007;47(05):240-241

5 Kosnik EJ, Meagher JN, Quenemoen LR. Parietal intradiploic encephalocele. Case report. J Neurosurg 1976;44(05):617-619

6 David DJ. Cephaloceles: classification, pathology, and management-a review. J Craniofac Surg 1993;4(04):192-202

7 David DJ, Proudman TW. Cephaloceles: classification, pathology, and management. World J Surg 1989;13(04): 349-357

8 Suwanwela C, Suwanwela N. A morphological classification of sincipital encephalomeningoceles. J Neurosurg 1972;36(02): 201-211

9 Patil AA, Etemadrezaie H. Posttraumatic intradiploic meningoencephalocele. Case report. J Neurosurg 1996;84(02):284-287

10 Lenthall R, Penney C. Growing skull fracture extending posteriorly to the superior sagittal sinus with intradiploic extension. $\mathrm{Br}$ J Radiol 1999;72(859):714-716

11 Martínez-Lage JF, López F, Piqueras C, Poza M. Iatrogenic intradiploic meningoencephalocele. Case report. J Neurosurg 1997; 87(03):468-471

12 Loumiotis I, Jones L, Diehn F, Lanzino G. Symptomatic left intradiploic encephalocele. Neurology 2010;75(11):1027

13 Menkü A, Koç RK, Tucer B, Akdemir H. Is skull fracture necessary for developing an intradiploic pseudomeningocele as a complication of head injury in adulthood? Acta Neurochir (Wien) 2004; 146(06):623-627, discussion 627

14 Eames FA, Waldman JB. CT of posttraumatic intradiploic pseudomeningocele of the skull base: a case report. AJNR Am J Neuroradiol 1991;12(05):985-987

15 Mahapatra AK, Tandon PN. Post-traumatic intradiploic pseudomeningocele in children. Acta Neurochir (Wien) 1989;100(3-4): $120-126$

16 Turgut M, Ozcan OE, Karaman CZ. Post-traumatic intra-osseous pseudomeningocele of the occipital bone. Australas Radiol 1998; 42(03):262-263

17 Fountas KN, Smith JR, Jenkins PD, Murro AM. Spontaneous motor cortex encephalocele presenting with simple partial seizures and progressive hemiparesis. Case report and review of the literature. Neurosurg Focus 2005;19(03):E10

18 Arevalo-Perez J, Millán-Juncos JM. Parietal intradiploic encephalocele: report of a case and review of the literature. Neuroradiol J 2015;28(03):264-267

19 D'Almeida AC, King RB. Intradiploic cerebrospinal fluid fistula. Report of two cases. J Neurosurg 1981;54(01):84-88

20 Lunardi P, Missori P, Artico M, Fortuna A. Posttraumatic intradiploic leptomeningeal cyst in an adult: case report. Surg Neurol 1991;35(06):475-477

21 Martínez-Lage JF, Martínez Pérez M, Domingo R, Poza M. Posttraumatic intradiploic arachnoid cyst of the posterior fossa. Childs Nerv Syst 1997;13(05):293-296

22 Peters J, Raab P, Marquardt G, Zanella FE. Intradiploic meningoencephalocele. Eur Radiol 2002;12(03):S25-27 